\title{
Proceeding
}

Supplementary Issue: Rio 2016 Olympic Games Fourth Anniversary Special Edition. Olympic Studies Forum, 21-24 October 2020. Olympic Studies Research Group, Pontifical Catholic University of Rio Grande do Sul (GPEO PUCRS), Brazil

\section{Communication strategies from the International Olympic Committee's (IOC) for the promotion of the Olympic Movement at the Winter Olympic Games PyeongChang 2018}

\section{As estratégias de comunicação do Comitê Olímpico Internacional (COI) para a promoção do Movimento Olímpico nos Jogos Olímpicos de Inverno Pyeongchang 2018}

\author{
CARLOS ROBERTO GASPAR TEIXEIRA $\triangle$, ROBERTO TIETZMANN, PAULA PUHL, ALESSANDRA \\ SCARTON, NELSON SCHNEIDER TODT, ALICE APELLANIZ, RICARDO CIMIRRO
}

Pontifical Catholic University of Rio Grande do Sul (PUCRS), Brazil

\begin{abstract}
This paper's research problem is to analyse the communication actions by the $10 \mathrm{C}$, which involve immersive technology, especially the $360^{\circ}$ image capturing, and how these contribute to the understanding of the Olympic Values. The excerpt chosen were the twenty-seven videos with immersive content available at the Olympic Channel in YouTube and in the free app, which required the use of Samsung Gear VR, that were related to the 2018 Winter Games in PyeongChang. The gathering was done between March and May 2018. To verify the recognition of the presence of the Olympic Values, a semi-structured questionnaire was done with 14 students from the Physical Education and the Social Communication courses of Pontifical Catholic University of Rio Grande do Sul. The students watched two videos categorized as: narrative and sportive. As a result, it was noticed that the video with a narrative predominance was the one in which the participants most identified the Olympic Values, whereas with the sportive video the athlete's experience was mostly highlighted, creating more sensorial experiences to the viewers.
\end{abstract}

Keywords: Virtual reality; Immersive technologies; Olympic Values; $360^{\circ}$ videos; Olympic Games.

Cite this article as:

Teixeira, C.R.G., Tietzmann, R., Puhl, P., Scarton, A., Todt, N.S., Apellaniz, A., \& Cimirro, R. (2021). Communication strategies from the International Olympic Committee's (IOC) for the promotion of the Olympic Movement at the Winter Olympic Games PyeongChang 2018 (in Portuguese). Journal of Human Sport and Exercise, 16(1proc), S49-S61. doi:https://doi.org/10.14198/jhse.2021.16.Proc1.05

Corresponding author. Pontifical Catholic University of Rio Grande do Sul (PUCRS), Brazil. http://orcid.org/0000-0001-68291682

E-mail: eu@ocarlosteixeira.com.br

Supplementary Issue: Rio 2016 Olympic Games Fourth Anniversary Special Edition. Olympic Studies Forum, 21-24 October 2020. Olympic Studies Research Group, Pontifical Catholic University of Rio Grande do Sul (GPEO PUCRS), Brazil.

JOURNAL OF HUMAN SPORT \& EXERCISE ISSN 1988-5202

(c) Faculty of Education. University of Alicante

doi:10.14198/jhse.2021.16.Proc1.05 


\section{RESUMO}

O artigo tem como problema de pesquisa analisar como as ações de comunicação do COI, que envolvem tecnologias imersivas, em especial a captação de imagens em $360^{\circ}$ e como estes contribuem para 0 entendimento dos Valores Olímpicos. 0 recorte escolhido foram os vinte e sete vídeos com conteúdos imersivos disponibilizados no Olympic Channel no Youtube e no aplicativo gratuito, que necessitavam a utilização dos óculos Samsung VR relacionados aos Jogos de Inverno de PyeongChang 2018. A coleta foi realizada entre os meses de março a maio de 2018. Para verificar o reconhecimento da presença de Valores Olímpicos foi realizado um questionário semiestruturado respondido por 14 estudantes pertencentes aos cursos de Educação Física e Comunicação Social da Pontifícia Universidade Católica do Rio Grande do Sul. Os estudantes assistiram dois vídeos categorizados como: narrativo e esportivo. Como resultado foi percebido que o vídeo com predominância narrativa foi onde os participantes mais identificaram os Valores Olímpicos, enquanto que com o vídeo esportivo foi mais destacada a experiência do atleta, gerando mais experiências sensoriais aos espectadores.

Palavras-Chave: Realidade virtual; Tecnologias imersivas; Valores Olímpicos; Vídeos 360; Jogos Olímpicos. 


\section{INTRODUÇÃO}

Esta pesquisa analisa como as estratégias comunicacionais do Comitê Olímpico Internacional (COI) testam e potencializam novos usos das tecnologias imersivas e sua utilização nos Jogos Olímpicos de Inverno de PyeongChang 2018, posteriormente também implementadas pela mídia em geral. Compreende-se ainda, na temática em questão, um estudo do material audiovisual enquanto ferramenta para a disseminação dos Valores Olímpicos.

A configuração de esporte popularizada atualmente está associada com o desenvolvimento de tecnologias novas de comunicação, sendo o aspecto que mais influenciou essa concepção recorrente na imprensa desde o início do século XX (Sobrinho, 2004). Os Jogos Olímpicos simbolizam o mais complexo megaevento esportivo que serve como referência para outros de grande porte como a Copa do Mundo de Futebol e os Jogos Pan-americanos (Matias, 2007). Megaevento é entendido como um acontecimento de curta duração, com resultados permanentes por longo tempo nas cidades e/ou países que o sediam e está associado à criação de infraestrutura e comodidades para o evento (Rocha, 1998).

Os Jogos Olímpicos, ao serem retratados pela mídia, são passíveis de sentidos que ultrapassam as informações fornecidas nas coberturas, baseando-se assim em sentidos construídos simbolicamente por meio de muitos "regimes da discursividade". E para Bourdieu (1977), esses diferentes sentidos produzem dois espetáculos: primeiro, no local e no instante do fato, por todo conjunto envolvido na competição e, segundo, por aqueles que transformam as imagens em discursos desse espetáculo.

\section{REALIDADE VIRTUAL E VÍDEOS $360^{\circ}$}

Os conteúdos em Realidade Virtual podem ser considerados uma das possíveis reproduções dos acontecimentos proposta por Bourdieu (1977), onde conforme Kirner (1996) busca-se estabelecer uma interface avançada com aplicações computacionais permitindo o usuário navegar e interagir, em tempo real, em um ambiente tridimensional gerado por computador usando dispositivos multissensoriais.

A Realidade Virtual é um conceito amplamente explorado ao se discutir as tendências e inovações tecnológicas presentes na comunicação. Conhecido também como VR (virtual reality), esse termo é compreendido e desenvolvido de diferentes formas por inúmeros autores. Krueger (1991) propôs o termo realidade artificial, destacando a interação humana em tempo real em ambientes virtuais gerados por computadores. Já Jaron Lanier, considerado o criador do termo realidade virtual, expandiu o significado do conceito, argumentando que interfaces dedicadas proporcionam uma imersão virtual por meio de um ambiente simulado e de equipamentos vestíveis (Rheingold, 1992), (Sherman; Craig, 2003), (Ryan, 2001). De acordo com Rheingold (1992) as tecnologias em VR consideram imersão e navegação como princípios básicos, onde são criadas cenas de computador nas quais o usuário, além de ter a ilusão de presença, tem a possibilidade de realizar ações nesses ambientes digitais.

Os constantes avanços tecnológicos e o desenvolvimento de aparatos que buscam proporcionar massivamente experiências com características similares a da realidade virtual aos consumidores, como por exemplo Google Cardboard e similares, auxiliaram na propagação e ampliação do conceito de VR. Segundo Jerald (2016), atualmente existem limitações tecnológicas nos sistemas de Realidade Virtual quanto a sua capacidade de imersão, contudo algumas alternativas são bastante atraentes. $O$ autor (ibidem) cita que essas diferentes realidades se relacionam com diferentes níveis de imersão e sentidos de presença disponíveis em diversos tipos de tecnologias. Nesse sentido, Fuchs (2017, p. 20) destaca que inúmeros 
graus de imersão podem ser representados de acordo com suas aplicações, como com os vídeos $360^{\circ}$, que podem atender a uma categoria imersiva definida pelo autor como "presença ou imersão visual". Tais tipos de vídeos são utilizados em dispositivos que apresentam limitações interativas em relação ao potencial prometido pelas tecnologias de RV. Conforme citam Pase, Vargas e Rocha (2018), a popularização de tecnologias que gravam conteúdos em $360^{\circ}$ ajudam na inserção da Realidade Virtual no imaginário, mas ao mesmo tempo corrompem sua compreensão por produzirem sensação de presença em ambientes digitais sem possibilitar que o usuário interfira no conteúdo.

Contudo, cabe destacar que para a presente pesquisa os vídeos $360^{\circ}$ foram considerados conteúdos em Realidade Virtual, mesmo que de forma básica, independente das diferenças conceituais existentes acerca do tema. Esses vídeos possuem destaque dentro das abordagens comunicacionais atuais por serem os conteúdos de caráter imersivo com maior viabilidade de produção e distribuição de massiva, comparados com outros tipos de tecnologias imersivas.

\section{VALORES OLÍMPICOS}

Considerando as formas de apropriação e vivência de valores relacionados ao esporte e à prática esportiva, os Jogos Olímpicos têm o poder simbólico de tornar vivo um conjunto de ideias, princípios e valores. Estes são propostos para que se mantenham de forma positiva na prática esportiva, refletindo e sendo o reflexo de ações também em nível educacional (DaCosta et al., 2008). Utilizado pela primeira vez em 1911, o termo Olimpismo, criado por Pierre de Coubertin, fundador do Movimento Olímpico Moderno, se refere:

[...] a uma filosofia de vida, exaltando e combinando de uma forma balanceada todas as qualidades do corpo, desejos e mente. Juntando o esporte com cultura e educação, o Olimpismo busca criar um estilo de vida baseado no prazer no esforço, no valor educacional do bom exemplo, responsabilidade social e respeito pelos princípios universais fundamentais de ética. (International Olympic Committee, 2015, p. 13, tradução livre do inglês)

O Olimpismo é uma filosofia que acredita que o esporte é universal e por isso pode ser usado como ferramenta na intercomunicação de diferentes culturas e como forma de educar os jovens. Devido a essa característica, o esporte pode ser utilizado para a aproximação de diferentes culturas e povos (Parry, 2003). Essa universalidade não se trata de tornar todas as culturas iguais, mas sim gerar um respeito mútuo entre todas as culturas, porque para haver globalidade se requer uma pluralidade cultural (He, 2001).

De acordo Tubino, Tubino e Garrido (2007), o Movimento Olímpico engloba todas as ações que envolvem o desenvolvimento do Olimpismo, com o objetivo de utilizar o esporte para educar a juventude e construir um mundo melhor e mais pacífico. Todas as ações do Movimento Olímpico são norteadas pelos Valores Olímpicos, que são amizade, excelência e respeito (Maass, 2007). Esses valores não são diretamente citados na Carta Olímpica, mas pode ser percebida uma relação entre eles e os princípios fundamentais do Olimpismo (ibidem).

A principal ação do Movimento Olímpico é os Jogos Olímpicos. Ao analisar os dados do site do COI, como nos Jogos Olímpicos de Verão de 2016, pode-se verificar que houve a participação de 11.238 atletas de 207 nacionalidades. Este número de países é maior que daqueles que são vinculados à Organização das Nações Unidas (ONU), que atualmente possui 193 países membros. Outra informação pode ser encontrada no site do Governo do Brasil (Portal Brasil, 2016) que diz que durante os Jogos de 2016, o Rio de Janeiro recebeu 
1,2 milhões de turistas, com isso pode-se chegar à conclusão de como este megaevento é universal e possibilita a relação entre diferentes culturas.

O Valor da Excelência é o prazer pelo esforço, não querer ser sempre melhor que o outro, mas sim dar 0 melhor de si. É sobre criar metas e buscar cumpri-las, não apenas buscar a vitória, participar sempre em busca do progresso e dar o seu melhor no seu dia a dia, sempre mantendo a saúde e o equilíbrio. Esse valor pode ser percebido no lema Olímpico Citius, Altius, Fortius (mais rápido, mais alto e mais forte) (Maass, 2007).

A Amizade possui uma relação com um dos valores primordiais do Olimpismo, a busca pela paz mundial, que se conecta com a "Ekecheiria", a trégua sagrada dos Jogos Olímpicos antigos na Grécia, que durante o período dos jogos, os cidadãos tinham um "salvo-conduto" para poderem ir até o santuário de Olímpia (Durántez, 1975). Além disso, a Amizade encoraja a todos a usar o esporte como forma de conexão entre diferentes pessoas e culturas, criando laços entre colegas de equipe e rivais independente das diferenças (Maass, 2007).

O Respeito se baseia em tratar de maneira igual não apenas os oponentes, mas a si mesmo, as regras, ao fair play e ao meio ambiente. Pode ser observado o comprometimento do Movimento Olímpico com esse valor em suas iniciativas contra o doping e suporte a igualdade de gênero no esporte (Maass, 2007).

Logo, a partir da crescente utilização de conteúdos com caráter imersivo (realidade virtual e vídeos $360^{\circ}$ ), buscou-se analisar como o COI utiliza essas tecnologias em seus canais oficiais para difundir os Valores Olímpicos.

\section{PROCEDIMENTOS METODOLÓGICOS}

As estratégias metodológicas utilizadas estão divididas em três etapas: (1) levantamento das ações de comunicação divulgadas em 2018 no site oficial do Comitê Olímpico Internacional, (2) reconhecimento da presença de Valores Olímpicos a partir das tecnologias encontradas na primeira etapa e (3) questionário anônimo semiestruturado composto por perguntas abertas e fechadas, aplicado aos respondentes a partir da apresentação de conteúdos imersivos presentes no site oficial do COI, no canal Olympic Channel no Youtube $^{1}$ e no aplicativo gratuito Olympic Channel2, ambos com a utilização do óculos Samsung VR ${ }^{3}$.

Na primeira etapa foram encontrados vinte e sete vídeos com conteúdos imersivos no site oficial do COI, entre os meses de março e maio de 2018 relacionados aos Jogos de Inverno de PyeongChang 2018, todos com a tecnologia de visualização em $360^{\circ}$. Eles abordaram entrevistas com atletas, cenas do treino das modalidades e também detalhes da vida pessoal. Contudo, o COI também realizou transmissões ao vivo dos Jogos Olímpicos de Inverno PyeongChang 2018 em Realidade Virtual ${ }^{4}$, porém os registros para análise

\footnotetext{
${ }^{1}$ A playlist com os vídeos da série Trending Gold está disponível em: < https://www.youtube.com/playlist?list=PL292yfpAFGZTn2mFLOxQQRRubqLZxzsf >. Acesso em: 21 nov. 2018.

2 Download disponível na Google Play < https://play.google.com/store/apps/details?id=com.olympicchannel.olympics\&hl=pt\&gl=US >, na Apple Store < https://itunes.apple.com/br/app/olympic-channel/id1129875600?mt=8 >. Os vídeos da série Seja 0 atleta estão na playlist do site oficial do Olympic Channel, disponível em: < https://www.olympicchannel.com/pt/video/detail/seja-o-atleta-bobsleighpyeongchang-2018-em-360 >. Acesso em: 21 nov. 2018.

${ }^{3}$ Samsung Gear VR. Disponível em: < https://www.samsung.com/global/galaxy/gear-vr/ >. Acesso em: 21 nov. 2018.

${ }_{4}^{4}$ Notícia completa disponível em: < https://www.oculus.com/blog/watch-the-2018-winter-olympics-on-gear-vr-with-nbc-sports-vr/ $>$ e < https://olympics.nbcsports.com/2018/01/09/virtual-reality-pyeongchang-olympics-vr-schedule > Acesso em 21 nov. 2018.
} 
não foram disponibilizados para consulta após a realização do evento. Cabe ressaltar também que as transmissões dos Jogos Olímpicos em RV não foram disponibilizadas para o Brasil.

A partir da análise dos vídeos encontrados, foi possível identificar um agrupamento em duas categorias principais: a) vídeos narrativos; b) vídeos esportivos. Os vídeos considerados narrativos pertenciam à série Trending Gold, de modo que as características prevalecentes eram: conteúdos mais narrativos intermediados por atletas, cenas desses praticando suas modalidades, relações interpessoais entre os próprios atletas e com os familiares e detalhes dos treinos das equipes. Além disso, a prioridade era abordar histórias além do esporte. Já os vídeos esportivos, que fazem parte da série Pyeongchang 2018 in 360, demonstraram a linguagem audiovisual com sequências de imagens rápidas, ênfase na prática esportiva sob a perspectiva do atleta (com a câmera em primeira pessoa), torcida retratada e destaque da vivência ao som de trilha sonora sem a locução de uma personagem. Ainda sobre os vídeos esportivos, eles ambientam o usuário ao simularem uma realidade não física que permite com o que a pessoa obtenha o ponto de vista do atleta em sua modalidade.

A fim de verificar o reconhecimento da presença de Valores Olímpicos foi realizado um questionário ${ }^{5}$ semiestruturado elaborado no Google Formulários composto por dezesseis perguntas, sendo quatro abertas e doze fechadas. O questionário foi o procedimento metodológico escolhido, pois a partir dele, informações como interesses, valores, conhecimentos e comportamentos foram coletadas (Gil, 2008). Os participantes assistiram a um vídeo de cada categoria identificadas na etapa 1, individualmente na sala, evitando assim interferência nas vivências e, no total, foram usados quatro óculos VR da Samsung para exibir os vídeos de Realidade Virtual e um computador para responder ao questionário. Para a técnica em questão, foi selecionada uma amostra composta por quatorze pessoas, divididas em dois grupos iguais de sete alunos dos cursos de graduação em Comunicação Social e em Educação Física. O questionário semiestruturado com perguntas abertas e fechadas foi dividido em três seções.

Na primeira seção foram coletadas informações para traçar um perfil dos participantes e foram obtidos dados como: idade, curso, soma da renda mensal de todos os moradores da casa, renda mensal própria, nível de escolaridade atual e identificação de gênero. Ao final da primeira seção do questionário também foram aplicadas perguntas fechadas sobre Realidade Virtual, como: "você tem conhecimento do que é Realidade Virtual?" e "você já consumiu algum material em Realidade Virtual?". Esses questionamentos buscaram identificar possíveis conhecimentos e experiências prévias da tecnologia utilizada. Na sequência foi exibido na íntegra o vídeo do COI, denominado Dream big: Nigeria's first ever women's Bobsleigh team6, correspondente aos vídeos narrativos.

Após assisti-lo, os integrantes assinalaram as palavras associadas aos Valores Olímpicos e aquelas que melhor representaram as sensações durante a experiência com Realidade Virtual. Elas foram escolhidas a partir de uma relação criada com os significados dos Valores Olímpicos e as demais estão associadas com a experiência de imersão por meio da Realidade Virtual. Os termos apresentados para os respondentes estavam divididas em três tipos: Valores Olímpicos, Realidade Virtual e outras sensações. Em seu discurso oficial durante a cerimônia de abertura da $127^{a}$ sessão do Comitê Olímpico Internacional, o presidente Thomas Bach utilizou diversas expressões para identificar os Valores Olímpicos, como diálogo, tolerância, fair-play, solidariedade (COI, 2014). Nesse sentido, tendo em vista que os Valores Olímpicos são definidos

${ }_{5}^{5}$ Questionário disponível em: < https://docs.google.com/forms/d/e/1FAlpQLSeMw5rcLHFxxg4vunXYAwwmrP-ej-alMiAplm2v9zYvU8tpQ/viewform?usp=sflink >. Acesso em: 21 nov. 2018.

6 Vídeo disponivel em: < https://www.olympicchannel.com/en/original-series/detail/trending-gold/trending-gold-season-season1/episodes/dream-big-nigeria-s-first-ever-women-s-bobsleigh-team >. Acesso em 14 jan. 2019. 
globalmente como Excelência, Amizade e Respeito, foram elaboradas outras possíveis palavras que, de alguma maneira, pudessem representar esses Ideais Olímpicos, como por exemplo: determinação, lealdade, persistência, amor, paz, etc. Para a Realidade Virtual foram usados termos como imersão, tontura, dor de cabeça, velocidade. Também foram utilizadas palavras alternativas que não se enquadravam diretamente dentro de Valores ou RV, mas com um viés de sensações que potencialmente poderiam remeter a outros sentimentos dos espectadores ao interagirem com os vídeos, sendo algumas delas: ânimo, confusão, calor, frio, confusão, etc.

Já no segundo vídeo, intitulado $B$ e the Athlete ${ }^{7}$, que representava os vídeos esportivos, o procedimento de assinalar as palavras depois de consumir o material foi realizado com os mesmos termos. Desse modo, foi possível comparar quais palavras e sensações foram marcadas depois de ver a um vídeo de cada categoria.

Na terceira seção da metodologia foi explicado para os integrantes que não possuíam conhecimento prévio no que consistem os Valores Olímpicos, a partir de um esquema imagético ${ }^{8}$ com os princípios sintetizados didaticamente pelo COI que são: Amizade, Respeito e Excelência. Após a explicação breve, os participantes responderam por meio de perguntas abertas quais desses Valores foram identificados ao longo dos vídeos, como se sentiram e em qual deles se obteve uma maior imersão e o porquê. Dessa forma foi possível realizar uma comparação entre as percepções dos vídeos (coletadas na etapa 2 a partir das palavras assinaladas) com os Valores Olímpicos (após a apresentação do esquema imagético). A partir da análise do desenvolvimento dessas três etapas foi possível analisar os resultados e inferir algumas tendências e conclusões.

\section{RESULTADOS E DISCUSSÃO}

A amostra coletada totalizou 14 respondentes, todos estudantes de graduação, metade cursando Educação Física e a outra metade cursando Comunicação Social (nos cursos de Relações Públicas, Publicidade e Propaganda e Jornalismo da Pontifícia Universidade Católica do Rio Grande do Sul - PUCRS). A maioria dos participantes, mais de 70\%, tinham de 17 a 20 anos, o restante possuía idade superior a 21 anos. Quase dois terços da amostra eram do sexo feminino. A renda familiar média mensal variou, em sua maioria (mais de $80 \%$ ), entre 0 e 15 salários-mínimos, enquanto a renda individual foi de até 1 salário-mínimo para mais de $90 \%$ dos pesquisados.

Quando questionados sobre Realidade Virtual, apenas uma pessoa afirmou não conhecer a tecnologia. Ao serem perguntados sobre o consumo de conteúdos em RV ou vídeos $360^{\circ}$, aproximadamente $71 \%$ já os utilizou. Após assistirem aos vídeos $360^{\circ}$, um com caráter narrativo e outro esportivo, os respondentes assinalaram as palavras que melhor representavam seus sentimentos ao participar da experiência imersiva. A partir desses resultados foram elaboradas as nuvens de palavras conforme as figuras 1,2 e 3 , onde as quanto maior a frequência da palavra, maior o seu tamanho.

\footnotetext{
7 Vídeo disponível em: < https://www.olympicchannel.com/en/video/detail/be-the-athlete-bobsleigh-pyeongchang-2018-in-360 >. Acesso em: 14 de jan. 2019.

${ }^{8}$ Esse esquema foi retirado do conteúdo educacional do projeto Transforma, uma parceria entre o Ministério da Educação e 0 Comitê Olímpico Internacional. Criado em 2014, o projeto busca capacitar professores de Educação Física, fornecendo documentos didáticos para ajudar no ensino de esportes pouco praticados no Brasil, além de conteúdo sobre a história, simbologia e os Valores Olímpicos.
} 


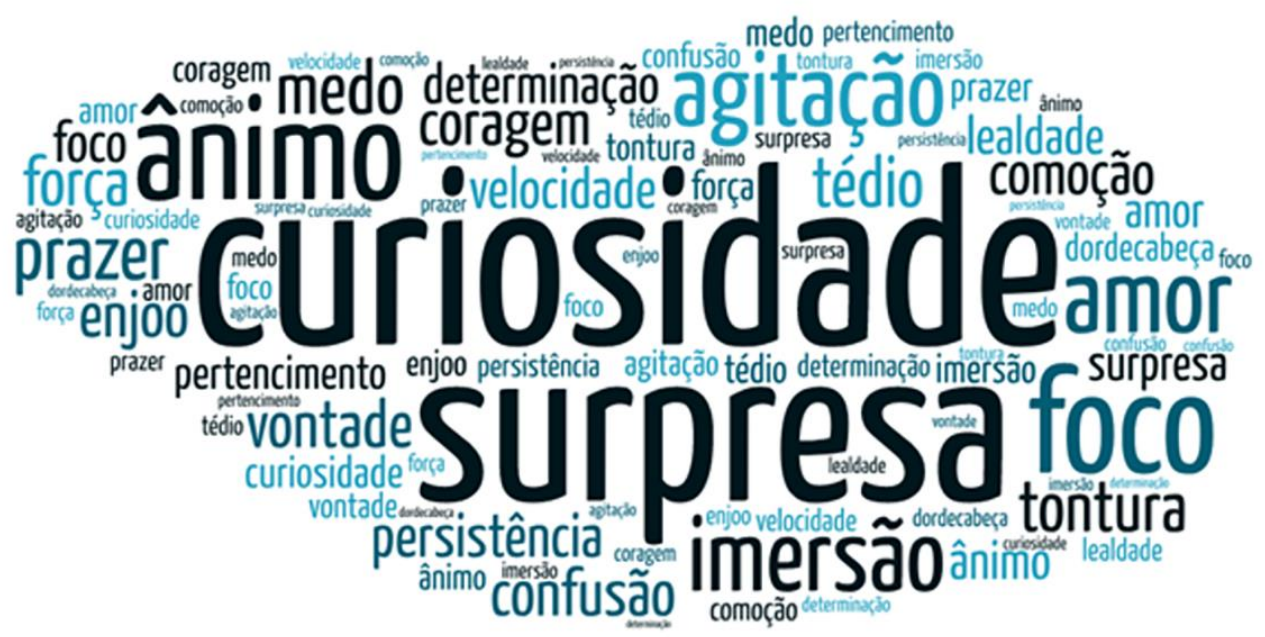

Fonte: Elaborada pelos autores a partir das respostas do questionário.

Figura 1. Nuvem com as palavras mais recorrentes na coleta para o vídeo 1 (narrativo).

Observa-se que nos vídeos de viés narrativo foram assinaladas sensações ligadas às palavras curiosidade, surpresa, ânimo, foco, amor e imersão. Nota-se a partir das respostas do vídeo que contava uma história sobre o desafio do atleta conseguiu captar a atenção dos respondentes pela imersão, proporcionada pela tecnologia (uso da captação em $360^{\circ}$ e dos óculos VR) e a curiosidade os fez estarem mais atentos ao escopo do vídeo e também trouxe mais atenção ao conteúdo. Essa atenção colaborou para despertar sentimentos como amor, comoção, ou seja, empatia com o personagem. Porém não se pode destacar os incômodos como tontura, confusão, enjoo, aspectos que muitas vezes podem prejudicar a compreensão narrativa e fazer o espectador perder o foco do que está assistindo, nesse sentido a imersão não ocorre por completo.

Na Figura 2, a seguir são apresentadas as respostas a partir do vídeo 2, com ênfase na prática esportiva.

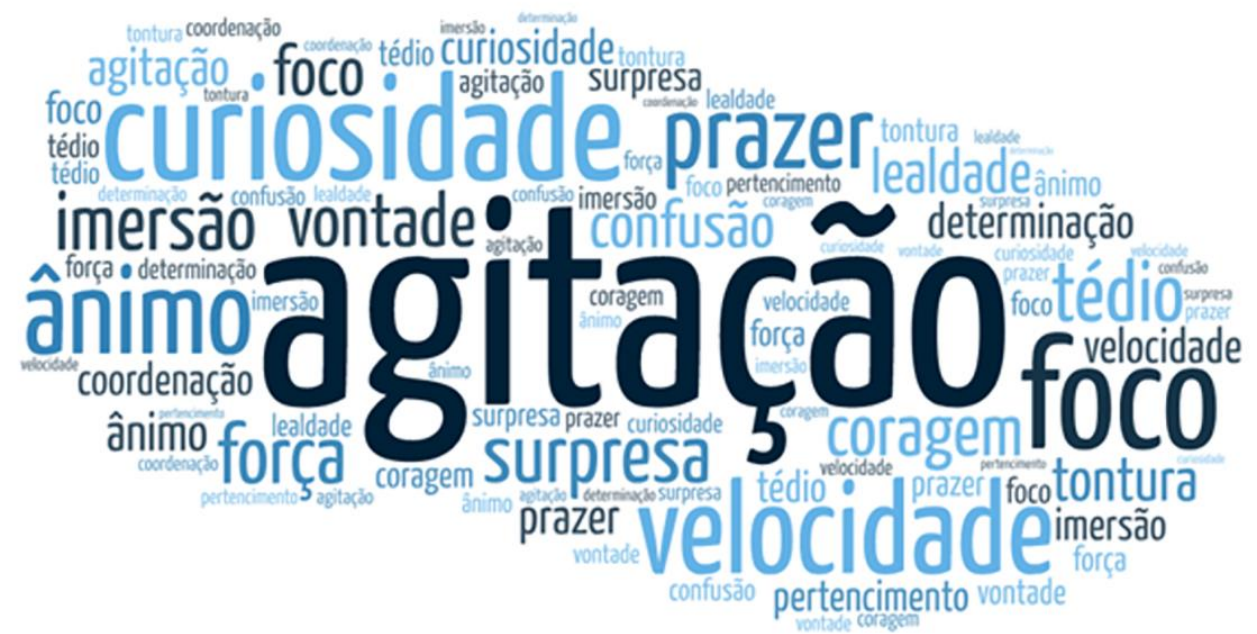

Fonte: Elaborada pelos autores a partir das respostas do questionário.

Figura 2. Nuvem com as palavras mais recorrentes na coleta para o vídeo 2 (esportivo). 
No vídeo considerado esportivo, prevaleceram sensações relacionadas às palavras agitação, foco, curiosidade, velocidade, ânimo e prazer. Além do foco e curiosidade já citados na Figura 1, sobre o vídeo narrativo, as palavras velocidade e agitação demonstram que a captação do conteúdo usando o recurso de $360^{\circ}$ que permite a navegação escolhida pelo usuário, trouxe um efeito diferenciado, que faz com que esse espectador sinta, mesmo de forma mediada, a sensação possibilitada pelo esporte mesmo não estando no local do acontecimento.

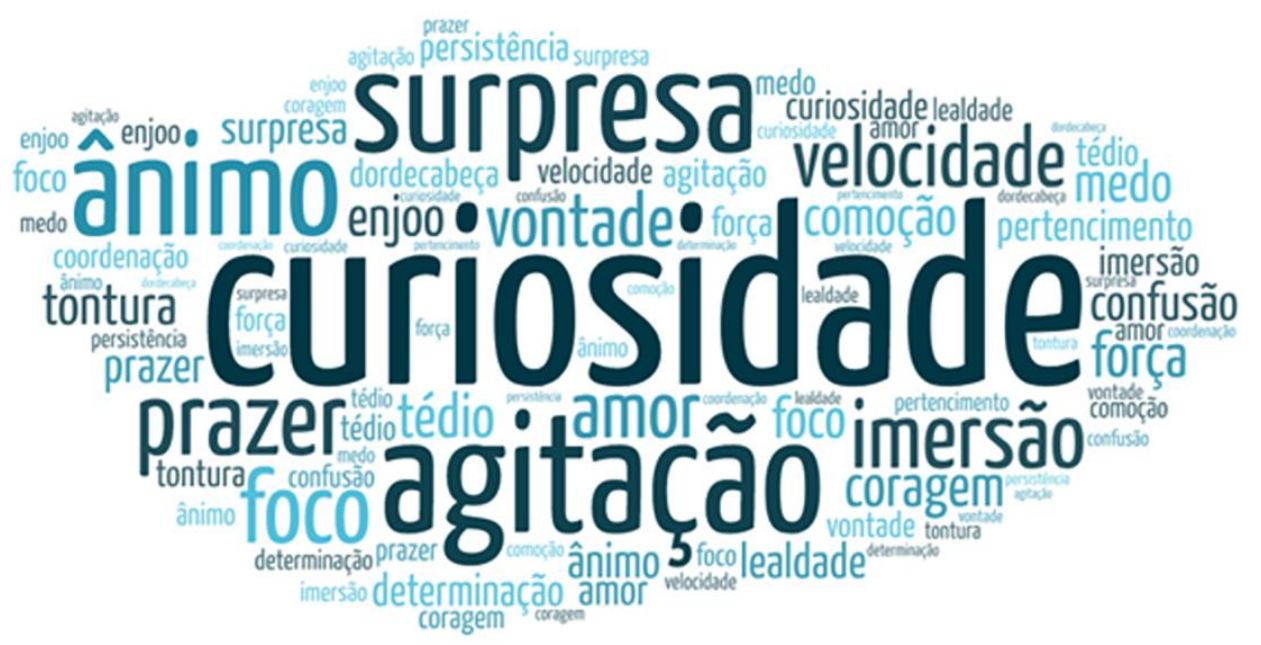

Fonte: Elaborada pelos autores a partir das respostas do questionário.

Figura 3. Nuvem com as palavras mais recorrentes na coleta para os dois vídeos.

Ao combinar as palavras mais frequentes nos dois vídeos foi possível observar que os sentimentos mais recorrentes se vinculavam a curiosidade, agitação, ânimo, surpresa, prazer e imersão. Desse modo, é possível observar que ao assinalar as palavras que demonstravam as principais sensações e percepções acerca dos vídeos apresentados, independente do tema contido, não se verificou uma relação com os termos que podem ser associados aos Valores Olímpicos, como: persistência, determinação, amor, paz, coragem, etc. $O$ foco principal das percepções despertadas pelos vídeos teve maior ênfase em sensações decorrentes ao caráter imersivo tecnológico das imagens em $360^{\circ}$.

Apenas 28\% afirmaram ter conhecimento prévio sobre os Valores Olímpicos. Dessa forma foi apresentada uma breve explicação acerca dos Valores Olímpicos por meio de um esquema imagético para posteriormente os pesquisados fossem respondidos as questões abertas. Todos os entrevistados afirmaram identificar algum dos valores olímpicos nos vídeos. $O$ vídeo narrativo foi segundo alguns dos entrevistados o que apresentou de forma mais clara os valores, conforme as falas a seguir: "Principalmente no primeiro, visto que foi demonstrado a história das nigerianas que treinam nos Estados Unidos", "[...] no primeiro vídeo foi passado o valor de amizade e no segundo não consegui identificar estes valores", "Acho que no primeiro aparece um pouco mais devido a narrativa da história das atletas, mas no primeiro se pode perceber traços de excelência e amizade", "[...] no primeiro vídeo, pois ele nos mostra o dia a dia das atletas nigerianas e isso nos mostrou muito os valores citados, como amizade e respeito", "no primeiro vídeo, em que a situação antes do esporte era precária e como o esporte mudou essa situação". Ao comparar os dois vídeos um dos entrevistados citou: 
No primeiro vídeo foi mais presente esses valores pelo contexto de vida dos atletas e pelas histórias contadas e demonstradas. Já o segundo não transmite esses mesmos valores por ter o enfoque na prática do esporte, mas por ser mais dinâmico dá uma sensação maior de envolvimento na prática esportiva em si.

De um modo geral ambos os vídeos conseguiram transmitir a essência dos Valores Olímpicos, como demonstra a citação a seguir: "[...] a história das atletas traz inspiração e celebra a união, amizade e perseverança que o grupo mantém", "a excelência fica explícita no desempenho dos atletas e no seu preparo mostrado no vídeo. O respeito e a amizade também se fazem presentes ao mostrar o relacionamento do atleta com os aparelhos que utiliza e entre si como equipe", "[...] o conjunto de atletas, nos mostra a amizade, o respeito entre eles e a excelência de cada atleta em treinamento", "[...] é notório a responsabilidade, amor entre o esporte e o atleta, respeito com colegas de equipe e excelência", "[...] a aproximação com a realidade permite um melhor entendimento e interesse, fazendo com que a gente se prenda ao que foi apresentado e enxergue esses valores, nas falas, gestos, imagens e sensações que o vídeo proporciona", "[...] mostra 0 trabalho árduo para melhorar suas habilidades. Integração entre escolas para novos atletas, respeitando as diferenças".

Ao serem questionados sobre qual vídeo apresentou maior sensação de imersão as respostas foram variadas. Os que argumentaram que o vídeo narrativo foi mais imersivo, citaram que o fato de haver uma história estar sendo contada auxilia no processo de imersão, "fiquei mais ligado a história dos atletas, suas trajetórias e pelo apelo emocional de superação", "gostei mais porque ele trouxe um contexto de ensinamento", "exigia movimentos meus para enxergar novas imagens e conteúdo, parecia mais real", "a experiência de imersão foi mais completa no vídeo que relatava sobre a atleta nigeriana", "achei ele mais interessante, me ver nas ruas da Nigéria foi empolgante", "Me senti mais imersa no primeiro [...]. Já 0 segundo oferecia pouco conteúdo $360^{\circ}$ e não exigia muito de mim, se tornando um tanto maçante".

Já os que consideraram o vídeo esportivo mais imersivo citaram as questões ligadas a emoção da prática esportiva em si: "[...] me senti imerso na prática específica do esporte", "[...] eu me senti animada, visto que ele trouxe a velocidade", "Senti uma maior imersão no segundo pela posição que a câmera estava", "O vídeo dois foi aquele em que eu senti mais o que se passava, tanto as sensações de frio na barriga quando estamos em alta velocidade até os movimentos feitos pelos atletas", "Me senti completamente naquela realidade. No segundo vídeo, pois tinha mais emoção e adrenalina", "O segundo vídeo como era mais rápido e com bastante adrenalina, eu me senti mais como se eu estivesse ali dentro", "gostei mais do segundo, pois há mais adrenalina", "me senti mais imerso no vídeo 2 por ter mais elementos onde eu poderia participar", "Me senti mais imerso no segundo vídeo, por ter um único cenário, que facilitou a concentração e possibilitou que eu explorasse melhor o local", "O segundo vídeo como era mais rápido e com bastante adrenalina, eu me senti mais como se eu estivesse ali dentro".

Quanto a sua preferência temática entre os vídeos, os resultados podem ser considerados equilibrados com uma leve vantagem para o narrativo - com $57,1 \%$ - contra 42,9\% para o esportivo. Ao expor os motivos que fizeram o narrativo ser considerado o melhor, os pesquisados destacaram a história e seu realismo: "Apesar de eu ter dito uma sensação de tédio no primeiro vídeo, eu gostei mais porque ele trouxe uma realidade das pessoas e um ensinamento", "[...] chama mais a atenção pela história contada e por todo o contexto comparado ao segundo que é mais dinâmico e ágil, porém não demonstra valores nem desenvolve uma história", "conta uma história, tem mais conteúdo e exigiu mais interação minha com a experiência", "história de superação que é contada e da rotina que também é mostrada", "[...] havia mais detalhes ao redor e conseguimos aproveitar o 360", "[...] mostrou um assunto muito interessante no qual eu não tinha 
conhecimento", "[...] contou como as mulheres nigerianas conseguiram ir para os Estados Unidos com o intuito de treinar e ainda constroem laços com meninas mais novas, para despertar nelas o interesse pelo esporte".

O vídeo esportivo foi preferido para alguns devido ao nível de imersão considerado mais alto: "[...] experiência de maior imersão e pelo apelo mais íntimo com a atleta, remetendo ao sentimento de pertencimento", "[...] me senti totalmente dentro daquele esporte", "[...] uma maior diversão, velocidade e emoção", "[...] traz muito mais ação e sensações em comparação ao outro vídeo", "[...] despertar mais os meus sentimentos e por ter melhor compreensão".

Todos os entrevistados consideraram que as novas tecnologias auxiliam na imersão do telespectador, destacando pontos como: "[...] maior imersão numa determinada realidade que muitas vezes não temos contato. Elas nos proporcionam um contato que a televisão (provavelmente maior meio de comunicação de massa), por exemplo, não nos dá", "[...] o telespectador consegue de uma certa forma entender como é estar ali", "[...] através da dinâmica podemos ter a mesma visão e sentimentos muito aproximados das realidades mostradas nos vídeos", "[...] o foco do telespectador fica refém da mídia que ele escolhe assistir. Não prestamos atenção em outras coisas e dedicamos $100 \%$ da atenção e tempo ao que está sendo transmitido. Fazemos parte plenamente daquilo, mesmo que indiretamente", "[...] essa tecnologia passa uma sensação real do que está acontecendo, incluindo o telespectador na situação", "[...] auxiliam no conhecimento de realidades que não são nossas".

A partir disso, podemos desenvolver a empatia e o respeito pelos esportistas ao vivenciar, mesmo que por poucos minutos, o que é a prática esportiva profissional e seus riscos, "[...] a tecnologia nos faz estar mais próximo do real, cada dia mais", "[...] sem essas novas tecnologias ele não teria muita graça", "[...] essa nova tecnologia auxilia uma perspectiva mais avançada sobre os sentidos do indivíduo", "[...] buscam cada vez mais trazer a experiência para um nível mais próximo da realidade", "[...] ter uma visão geral e mais próxima dos locais e das pessoas, poder movimentar o corpo e sentir a fundo diversas sensações".

\section{CONSIDERAÇÕES FINAIS}

Conforme os relatos dos respondentes citados anteriormente, pode-se inferir que o vídeo com predominância narrativa foi onde os participantes mais identificaram os Valores Olímpicos e chama a atenção que após assisti-lo, foi constatado que o uso de tecnologias imersivas não apresentou influência direta na forma como o espectador interpretou o conteúdo da narrativa, o que sugere que o conteúdo narrativo e a forma com que foi conduzido pelos criadores do vídeo prevaleceu. No entanto a articulação com a captação certamente colaborou para essa percepção dos espectadores, mesmo que estes não tenham destacado o uso da captação das imagens em $360^{\circ}$.

Enquanto no vídeo com predomínio sensorial, foi destacado a importância do formato $360^{\circ}$, pois no momento em que a imersão aguçou os sentidos dos participantes da experiência, estes conseguiram ter a sensação de estar presente na mesma ação do atleta, ou seja, ter uma "sensação" mais próxima da vivência esportiva.

O presente estudo sugere que a utilização de tecnologias imersivas pelo COI não apresenta até então, um papel que possa ser considerado fundamental na promoção do Movimento Olímpico. $O$ fato de os vídeos analisados serem em $360^{\circ}$ se mostrou indiferente para um maior entendimento dos Valores Olímpicos. Como hipóteses o estudo apontou que essa constatação pode estar fundamentada na falta de conhecimento 
do público investigado sobre quais são do Valores Olímpicos e por isso talvez sejam necessários mais conteúdos que expliquem e debatam mais diretamente esses conceitos.

Nesse sentido, as experiências imersivas podem ser aliadas para a construção de narrativas que destaquem os Valores Olímpicos, tendo cuidados em permitir ao usuário uma navegação mais guiada e pontuada para que ele não perca o fio narrativo e consiga ao final ter mais foco sobre o conteúdo proposto. Dessa forma, entende-se que mesmo com a utilização de tecnologias imersivas, a forma de contar uma história ainda é a premissa principal para divulgação e compreensão de conteúdos, tentando despertar sentimentos e interesse por parte do público.

\section{REFERÊNCIAS}

Bourdieu, P. (1997). Sobre a televisão. Tradução Maria Lucia Machado. Rio de Janeiro: Jorge Zahar. COI. (2014). Discurso oficial durante a cerimônia de abertura da sessão $127^{a}$ do COI, Mônaco, 7 dez. Retrieved form: <https://www.olympic.org/documents/olympic-agenda-2020>. Acesso em: 14 nov. 2018.

DaCosta, L. et al. (2008). Legado de Valores dos Jogos Olímpicos: dos "Mega" aos "Micro" Eventos. Ministério do Esporte. Brasília.

Durantez, C. (1975). Olímpia y los Juegos Olímpicos antigos. Madrid: Delegación Nacional de Educación Física e Desportes, Comitê Olímpico Espanhol.

Fuchs, P. (2017). Virtual Reality Headsets: A theoritical and pragmatic approach. London: CRC Press. https://doi.org/10.1201/9781315208244

Gil, A.C. (2008). Métodos e técnicas de pesquisa social. 6. ed. São Paulo: Atlas.

$\mathrm{He}$, Z. (2001, October-November). Universal Olympic values in a multicultural world. Olympic Review, pp. 11-13.

IOC. (2015). Olympic Charter, Lausanne: IOC.

Jerald, J. (2016). The VR Book: Human-centered design for virtual reality. Illinois: Morgan \& Claypool Publisher. https://doi.org/10.1145/2897826.2927320

Kirner, C. et al. (1996). Realidade Virtual Aumentada: conceitos, projeto e aplicações. In: IX Symposium on Virtual and Augmented Reality. Sociedade Brasileira de Computação. Rio de Janeiro.

Krueger, M. (1991). Artificial Reality 2. Addison-Wesley Professional.

Maass, S. (2007). Olympic Review 64. Lausanne: IOC.

Matias, M. (2008). Os efeitos dos megaeventos esportivos nas cidades. Turismo e Sociedade, v. 1, n. 2. https://doi.org/10.5380/tes.v1i2.12934

Parry, J. (2003). Olympism for the 21st Century. Centre d'Estudis Olímpics (CEO). Universitat Autònoma de Barcelona (UAB).

Pase, A.F.; Vargas, F. P.; Rocha, G.G. (2018). Mapeamento das possibilidades de conteúdo interativo imersivo jornalístico. In: Congresso Brasileiro de Ciências da Comunicação, 41, Joinville. In: Anais do $41^{\circ}$ Congresso Brasileiro de Ciências da Comunicação. São Paulo: Intercom, p. 1-15. Retrieved from: <https://portalintercom.org.br/anais/nacional2018/resumos/R13-0729-1.pdf>. Acesso em: 08 nov. 2018.

Portal Brasil. (2016). Rio recebeu 1,2 milhão de visitantes durante Jogos Olímpicos. Governo do Brasil, Brasília, 28 ago. 2016, 10:23.

Rheingold, H. (1992). Virtual reality. Londres: Mandarin.

Rocha, E. (1998). Cultura e idolatria: ilusão, consumo e fantasia in Cultura e Imaginário: interpretação de filmes e pesquisa de idéias. Helal, R. (org.).

Ryan, M.L. (2001). Immersion and in literacture and eletronic media. Baltimore: Johns Hopkins. 
Sobrinho, D.C. (2004). O importante é... Breves considerações sobre aspectos das relações entre mídia e esporte. In: Anais do $27^{\circ}$ Congresso Brasileiro de Ciências da Comunicação. São Paulo: Intercom. Retrieved from:

<http://www.portcom.intercom.org.br/pdfs/75440349957597230095317192130503520236.pdf>. Acesso em: 14 jan. 2019.

Sherman, W.R.; Craig, A.B. (2003). Understanding Virtual Reality: Interface, Application and Design. São Francisco: Morgan Kaufmann. https://doi.org/10.1162/105474603322391668

Tubino, M. J. G.; Tubino, F. M. e Garrido, F. A. C. G. (2007). Dicionário Enciclopédico Tubino do Esporte. 1 ed. Rio de Janeiro: Senac. 